\title{
PROJETO CANTARIA - EDUCAÇÃO E ARTE PARA CRIANÇAS: REUTILIZAÇÃO, SEPARAÇÃ̃O E RECICLAGEM DO LIXO
}

Camilla Kiemy Nakagawa Fonseca - camillakiemy@gmail.com

Universidade Federal de Ouro Preto

Morro do Cruzeiro, $s / n$, Bauxita

35400-000 - Ouro Preto - Minas Gerais

Francielle C. Nogueira -francielle.nogueira@ufop.edu.br

Universidade Federal de Ouro Preto

Morro do Cruzeiro, $s / n$, Bauxita

35400-000 - Ouro Preto - Minas Gerais

Carlos Alberto Pereira - pereiraufop@gmail.com

Universidade Federal de Ouro Preto

Morro do Cruzeiro, s/n, Bauxita

35400-000 - Ouro Preto - Minas Gerais

Resumo: O projeto de extensão "Educação e Arte para crianças" que em 2020 completa 20 anos é desenvolvido no Departamento de Engenharia de Minas da UFOP e abrange a comunidade ouro-pretana, graduandos de diversos cursos e crianças na faixa etária de 11 anos provenientes de escolas públicas de Ouro Preto. Trabalhando, ao longo desses anos com educação patrimonial, cidadania e ética, o projeto decidiu recentemente ampliar o seu escopo para resíduos com foco na reutilização, separação e reciclagem do lixo doméstico, criando nas crianças a conscientização sobre a importância de cada um cuidar do seu próprio lixo e sobre a necessidade do consumo consciente. Para tanto, foi montada uma gincana em que as crianças foram orientadas a separar o lixo reciclável gerado em casa levando-o para as dependências do projeto durante todo o semestre. Os monitores ficaram responsáveis pelo recebimento, contabilização, separação correta destes materiais que seriam destinados ao lixo. Com o objetivo de trabalhar o conceito de reutilização, foram criados brinquedos com parte do material recolhido, permitindo dessa forma que as crianças desenvolvessem a imaginação e criatividade. Os alunos que trouxeram a maior quantidade de lixo reciclável foram premiados em primeiro, segundo e terceiro lugares. Ao final do projeto foram contabilizados $202 \mathrm{~kg}$ de material reciclado que foi doado a associação de catadores de lixo denominada "Ouro Preto Recicla". Por fim, destaca-se a importância da criação de práticas cidadãs, que como este projeto, contribuem para a formação de crianças conscientes, críticas e comprometidas com o futuro do planeta.

Palavras-chave: Crianças. Reutilização. Separação. Reciclagem. Lixo. 


\section{INTRODUÇÃO}

A cada dia, a humanidade vivencia tragédias no meio ambiente em função da má destinação e do excesso de lixo jogado na natureza, tornando-se um problema que prejudica a sobrevivência dos seres vivos no planeta (LOPES, 2007). Entre os impactos ambientais negativos que podem ser originados a partir do lixo urbano produzido estão os efeitos decorrentes da prática de disposição inadequada de resíduos sólidos em fundos de vale, às margens de ruas ou em cursos d'água. Essas práticas habituais podem provocar, entre outros danos, contaminação de corpos d'água, assoreamento, enchentes, proliferação de vetores transmissores de doenças - tais como ratos, baratas, moscas, vermes. Soma-se a isso a poluição visual, o mau cheiro e a contaminação do ambiente (MUCELIN e BELLINI, 2008). Deacordo com a Associação Brasileira das Empresas de Limpeza Pública e Resíduos Especiais (Abrelpe), o Brasil produziu, em média, 79 milhões de toneladas de lixo em 2018. Comparado com países da América Latina, é o país que mais gera lixo. Além disso, a tendência de crescimento na produção de resíduos deve ser mantida nos próximos anos e, conforme a previsão de estudiosos do assunto, o Brasil alcançará, em 2030, uma média anual de 100 milhões de toneladas de lixo (COELHO, 2020).

No entanto, há medidas mitigadoras que podem ser tomadas e uma delas é a reciclagem (LOPES, 2007). Por meio dela, o lixo passa a ser visto de outra maneira, não mais como um final, mas como o início de um ciclo em que se podem preservar o meio ambiente, incentivara participação consciente e a transformação de hábitos de todos (MARODIN e MORAIS, 2004). A maior aliada dos programas de reciclagem é a coleta seletiva. A sociedade deve ser bem orientada a separar corretamente os materiais usados na reciclagem, tais como papel, vidros, plásticos e metais (RODRIGUES e CAVINATTO, 1997).

Pode-se entender que a educação ambiental é um processo pelo qual o educando começa a obter conhecimentos acerca das questões ambientais, por meio dos quais ele passa a ter uma nova visão sobre o meio ambiente, tornando-se um agente transformador em relação à conservação ambiental. A cada dia a questão ambiental tem sido considerada um fato que precisa ser trabalhado com toda a sociedade, principalmente nas escolas, pois as crianças bem informadas sobre os problemas ambientais serão adultos mais preocupados com o meio ambiente. Além do que, elas vão ser transmissoras dos conhecimentos que obtiverem na escola sobre as questões ambientais em suas casas, famílias e vizinhanças (MEDEIROS et al., 2011). As universidades possuem projetos de extensão cujo papel é integrar a comunidade acadêmica com a sociedade, alinhando o conhecimento científico do ensino e da pesquisa com as necessidades de todos. A universidade, ao se inserir na comunidade, interage e busca a transformação da realidade social, por isso é de suma importância a criação de projetos que orientem os indivíduos, principalmente as crianças, sobre a importância da reciclagem e da educação ambiental.

Sabe-se da existência de um projeto de extensão realizado na Universidade Federal do Rio Grande do Sul denominado "Reciclar é Vida", que implementa a coleta seletiva de lixo na Instituição e destina os resíduos a cooperativas de catadores. Como resultado, gera trabalho, fazendo aumentar a renda familiar dos trabalhadores das associações e, consequentemente, a qualidade de vida dos envolvidos e de toda a comunidade, além da contribuição com o meio ambiente (VALLE. 2012). São ações como essa que inspiram outros projetos para que um dia a reciclagem seja um hábito de toda a sociedade.

O município de Ouro Preto, Minas Gerais, desenvolve, desde 2017, o programa "Ouro Preto Recicla", que foi criado com o intuito de ofertar a coleta seletiva na cidade a partir de uma parceria entre a prefeitura e duas associações de catadores - a Associação de Catadores de 
Materiais Recicláveis da Rancharia (ACMAR) e a Associação de Beneficiamento e Reciclagem do Lixo e Meio Ambiente e Preservação Ambiental da Cidade de Ouro Preto (Associação de Catadores do Padre Faria). Em fevereiro de 2018, nas entidades que promovem a coleta seletiva e reciclagem no município, foram coletados e tratados corretamente mais de 100 toneladas de resíduos, de acordo com o relatório da Secretaria Municipal de Meio Ambiente de Ouro Preto. No ano de 2019, o projeto de extensão "Educação e Arte para crianças" - que ocorre desde 2002 na Universidade Federal de Ouro Preto - cujo objetivo é promover conscientização patrimonial, cultura, arte e educação para crianças de escolas públicas do município de Ouro Preto, ampliou suas vertentes incluindo a educação ambiental, a qual envolve consumismo, reutilização, separação e reciclagem de resíduos. O objetivo principal desse novo olhar foi incentivar e instruir as crianças de escolas públicas a separarem o lixo doméstico, reciclarem e reutilizarem, além de conscientizá-los sobre a importância de cada indivíduo cuidar do seu lixo e fazê-los refletir sobre a real necessidade de aquisição de algo novo, indicando, assim, os problemas do consumismo. Desse modo, as crianças aprendem como é possível reutilizar e reciclar o lixo. Sabe-se, portanto, que esse aprendizado poderá influenciar os pais e os familiares destas a praticarem a reutilização e a reciclagem do lixo, gerando um futuro mais consciente e uma geração menos consumista.

\section{METODOLOGIA}

O projeto "Educação e Arte para as crianças" foi criado em 2002 e é desenvolvido pelo Departamento de Engenharia de Minas da Universidade Federal de Ouro Preto, com o apoio de graduandos, voluntários e bolsistas, de diversos cursos. O público alvo do projeto são alunos de 10 e 11 anos dos quintos anos das escolas municipais e estaduais da cidade de Ouro Preto. Realizado nas terças e quintas-feiras, à tarde, no campus da Universidade, o projeto tem como objetivo principal levar educação patrimonial, cidadania e ética para as crianças. No ano de 2019, foram ampliadas as vertentes e incluiu-se a educação ambiental com foco na reutilização, separação e reciclagem do lixo doméstico visando, assim, conscientizar as crianças da preservação do meio ambiente. Esse será o tema de discussão neste artigo.

\subsection{Apresentação da temática}

Em todas as aulas no decorrer do projeto, as atividades sobre os assuntos abordados foram pensadas contemplando a ludicidade, por meio de atividades interativas e práticas. Inicialmente, apresentou-se uma aula expositiva e introdutória. Posteriormente, as crianças fizeram um brinquedo reaproveitando garrafas pets e, ao final, apresentou-se a proposta da realização de uma gincana para promover a reciclagem do lixo gerado nas casas das crianças. Essa gincana foi desenvolvida durante os seis meses em que as aulas do projeto foram ofertadas.

A aula expositiva, realizada por meio de slides em Power Point, abordou definições sobre lixo, suas possíveis destinações, as consequências de sua destinação incorreta, o tempo de decomposição de alguns materiais e os cuidados necessários a ter. Além disso, trabalhou-se a política dos $5 \mathrm{Rs}$, que resumem os passos para um desenvolvimento sustentável, sendo eles: reduzir, recusar, reciclar, reutilizar e repensar. Esses conceitos foram transmitidos de forma lúdica e por meio de slides. As cores utilizadas na separação do lixo para a reciclagem, a importância da separação e os pontos de coleta seletiva na cidade de Ouro Preto também foram apresentados durante a aula. Ademais, as maneiras de reaproveitar o lixo foram explicadas e enfatizou-se a importância do reaproveitamento do lixo, para evitar que sejam descartados materiais que podem ainda ter outras funções. 
Por fim, as crianças fizeram uma atividade de reaproveitamento de garrafas pet para elaborar o brinquedo Bilboquê, que consiste em uma bola provida de um furo, ligada por uma corda a um bastonete côncavo em uma das extremidades e pontudo na outra, onde ela deve ser, respectivamente, aparada ou encaixada depois de atirada para o ar. Usou-se tampas degarrafas pet como bola, a parte superior da garrafa, devidamente cortada, como o bastonete côncavo, e barbante como a corda.

Ao propor a gincana de reciclagem, as crianças foram convidadas a separarem o lixo reciclável gerado em casa e a levarem-no para as dependências do projeto "Educação e Arte para crianças". Os monitores receberam o lixo trazido pelas crianças durante todos os dias de aulas do projeto. Antes do início das aulas, o lixo foi pesado e o valor anotado em uma planilha que continha os nomes dos alunos e as datas das aulas. Em todas as aulas o aluno que levasse a maior quantidade de material era premiado naquela data. Houve uma aula para instruir sobre a separação do lixo arrecadado em categorias (Figura 1). Para isso, os monitores prepararam luvas, máscaras e óculos de proteção. Em seguida, as sacolas de lixo trazidas pelos alunos foram abertas e despejadas para que os mesmos, juntamente com os monitores, pudessem separar os resíduos. Os monitores auxiliaram os alunos, mostrando-os quais eram os lixos recicláveis e quais não eram. Concluindo o projeto, os três primeiros lugares com a maior quantia de lixo reciclável foram premiados e todo o resíduo foi destinado à Associação de Catadores de Materiais Recicláveis da cidade. Essa competição para levar o prêmio instigou a participação das crianças e tornou a atividade lúdica.

Figura 1 - Crianças separando o lixo coletado

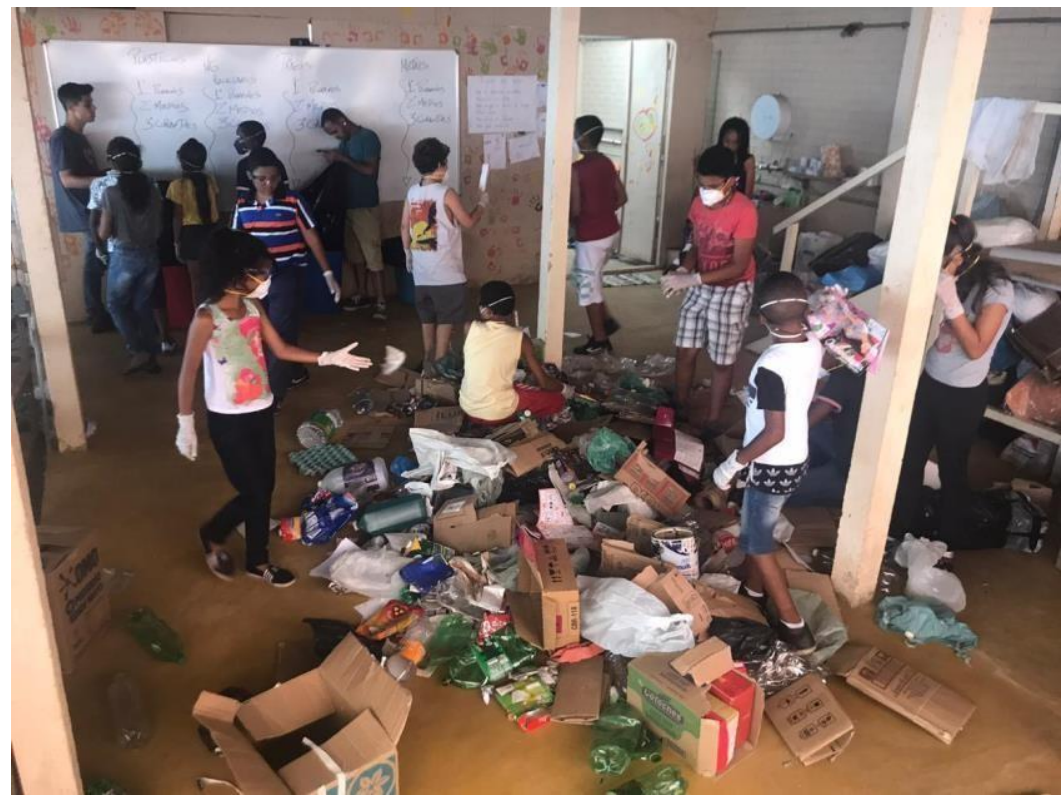

Fonte: Autores

\section{DISCUSSÕES E RESULTADOS}

\subsection{Preparação dos monitores}

Durante o semestre, houve a necessidade de os monitores visitarem a Associação de Catadores de Material Reciclável do Padre Faria (ACMRPF) para aprofundar seus conhecimentos sobre a reciclagem de lixo, entender como funciona a coleta seletiva e repassar informações para as crianças que se mostraram interessadas no assunto. 
Após a visita à Associação, os monitores elaboraram um banner com a classificação de resíduos recicláveis e não recicláveis para auxiliar as crianças a separarem o lixo que seria destinado à coleta seletiva (Quadro 1).

Quadro 1 - Classificação para a separação do lixo em categorias

\begin{tabular}{|c|c|c|}
\hline & RECICLÁVEL & NÃO RECICLÁVEL \\
\hline PAPEL & $\begin{array}{l}\text { Jornais, revistas, cartões, } \\
\text { cartolinas, folhas de caderno, } \\
\text { livros, papelão. }\end{array}$ & $\begin{array}{l}\text { Papéis sujos, guardanapos, } \\
\text { pontas de cigarro, etiquetas } \\
\text { adesivas, papel carbono, papel } \\
\text { higiênico, absorvente, papéis } \\
\text { plastificados e fita crepe. }\end{array}$ \\
\hline PLÁSTICO & $\begin{array}{l}\text { Embalagens de materiais de } \\
\text { limpeza e shampoo, copos de } \\
\text { café, tubos, canos, potes de } \\
\text { margarina, garrafas pet no geral. }\end{array}$ & $\begin{array}{l}\text { Cabos de panelas, tomadas, } \\
\text { embalagens de biscoitos (ou } \\
\text { qualquer embalagem metalizada } \\
\text { em seu interior). }\end{array}$ \\
\hline METAL & $\begin{array}{c}\text { Latas de alumínio, latas de aço, } \\
\text { tampas, ferragens, canos, latas } \\
\text { de tinta, latas de molho ou de } \\
\text { milho. }\end{array}$ & $\begin{array}{l}\text { Clips, grampos, esponjas de aço } \\
\text { e pilhas (essas têm um descarte } \\
\text { específico). }\end{array}$ \\
\hline OUTROS & & Isopor \\
\hline \multicolumn{3}{|c|}{$\begin{array}{l}\text { OBSERVAÇÃO: Vidros também são recicláveis, mas, por segurança, foi } \\
\text { solicitado que as crianças não levassem esse material. }\end{array}$} \\
\hline
\end{tabular}

A ACMRPF é coordenada por Maria das Graças Santos Carvalho e foi criada em 2012 de acordo com a Assessoria de Comunicação da Prefeitura de Ouro Preto, com a finalidade de melhorar as condições de trabalho e renda das famílias que vivem da separação de resíduos sólidos. Segundo a coordenadora, a Associação é de grande importância para Ouro Preto porque oferece qualidade de vida, recicla o material descartado e, assim, também gera emprego e diminui o impacto ambiental. Ademais, a porcentagem de lixo reciclável na cidade é cerca de $7 \%$ do lixo gerado, valor bem abaixo do esperado, o que reforça, cada vez mais, a importância de os cidadãos aderirem à coleta seletiva.

Uma dessas parcerias é realizada com a Prefeitura de Ouro Preto, em que uma das responsabilidades da Associação é promover o programa "Ouro Preto Recicla", que atende 10 bairros do município de Ouro Preto e, também, o distrito de Lavras Novas. Implementado em 2017, o programa possibilitou a criação de cinco empregos diretos e um aumento de mais de $30 \%$ na reciclagem do lixo em relação aos anos anteriores, e, em determinadas épocas do ano, é possível coletar, processar e destinar para a reciclagem aproximadamente 100 toneladas de material por mês. A Prefeitura de Ouro Preto também auxilia a Associação com o aluguel do galpão onde fica a sede da Associação e também com pagamento de contas de luz e de telefone.

Além do apoio da Prefeitura Municipal de Ouro Preto, a Associação conta com a parceria da Samarco, da UFOP, do IFMG, da Cooperouro, do Fórum, da Fundação Gorceix e de várias outras empresas.

\subsection{Separação do lixo coletado pelas crianças}

No momento da separação do lixo, percebeu-se que alguns itens do material trazido pelas crianças não eram recicláveis - embalagens metalizadas por dentro, como as de biscoitos, por 
exemplo. Esse momento foi uma oportunidade para os monitores explicarem detalhes da coleta seletiva e sobre o processo da reciclagem, levando a turma ao sucesso da atividade proposta (Figura 2).

Nesse momento, os monitores puderam reforçar que a reciclagem vai além da separação do lixo e que o cuidado com o meio ambiente envolve a forma como utilizamos os recursos do planeta. Mostraram como o consumo de bens de forma exagerada, ou seja, o consumismo, pode interferir no equilíbrio da natureza. As crianças foram convidadas a fazerem reflexões sobre pequenas atitudes que podem ser alteradas no cotidiano, como no momento de realizar uma compra, em que se pode dar preferência a produtos que sejam fabricados com embalagens recicláveis ou àquelas cujas embalagens possam ter outra utilidade após o consumo do produto original. Além disso, mostrou-se que os produtos com embalagens retornáveis ou refil possuem, geralmente, menor custo e devem ser também uma opção. Ensinou-se sobre a importância da utilização de sacolas reutilizáveis durante as compras em supermercado, mostrando que um número expressivo de sacolas plásticas vão parar em rios e nos mares, causando a morte de muitos peixes e animais marinhos. Também foram dadas dicas de reaproveitamento, como a utilização de folhas de um caderno do ano anterior para elaboração de rascunhos ou para estudo.

Figura 2 - Lixo devidamente separado pelas crianças e pronto para ser encaminhado para a Associação de Catadores de Materiais Recicláveis

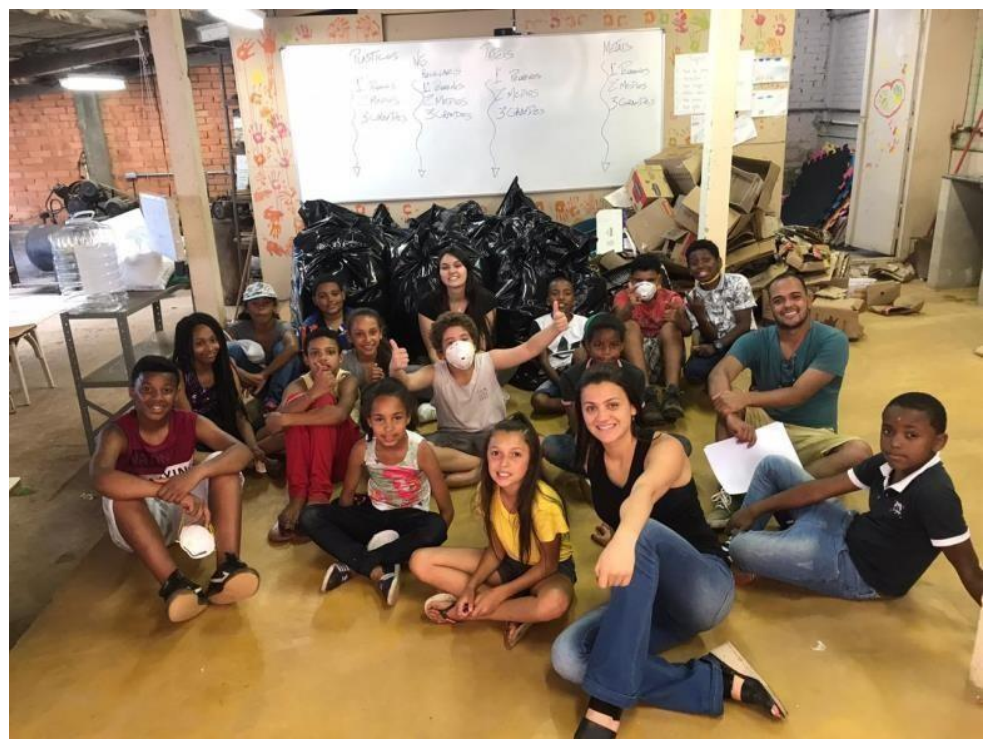

Fonte: Autores

\subsection{Coleta do lixo}

Já no primeiro dia do recolhimento do lixo trazido pelas crianças, foi observada a adesão massiva dos alunos e dos pais, que participaram ativamente ajudando seus filhos a levarem o lixo até o projeto.

Após o encerramento do projeto, contabilizou-se que $73,7 \%$ das crianças aderiram à nova vertente proposta, gerando o total de $202,18 \mathrm{~kg}$ ao final dos seis meses.

\subsection{Premiação dos alunos}

Ao final do projeto "Educação e Arte para crianças", com a presença dos diretores das escolas e pais das crianças participantes, realizou-se a premiação.

Pode-se destacar que, mais importante que a quantidade de lixo recolhida com o projeto, foi a contribuição para a educação ambiental das crianças e o envolvimento dos pais e da 
comunidade com esse projeto de extensão. Por meio da difusão de informações sobre coleta seletiva, houve a ampliação da cultura da reciclagem, algo que é muito importante para a cidade, uma vez que os bairros onde a maioria das crianças residem não faz parte da rota fixa de coleta seletiva. Sendo assim, os moradores que desejam reciclar precisam ligar para a Associação que recolhe o material em domicílio sob demanda. Nesse caso, o telefone de contato da Associação foi disponibilizado.

Foi de suma importância ensinar para as crianças que elas podem preservar o planeta e que todos podem ajudar com atitudes simples. Reutilizar embalagens ou algo que seria descartado, tomar banhos em tempo reduzido, fechar a torneira enquanto escova os dentes, não jogar lixo na rua e dar sempre o destino correto para o lixo, são exemplos de atitudes simples que podem contribuir para a preservação do meio ambiente. Isso é a educação ambiental. São atitudes que, se imputadas nas crianças, podem disseminar uma cultura de preservação ambiental.

$\mathrm{Na}$ atividade de construção do brinquedo Bilboquê, trabalhou-se o conceito da reutilização e os alunos puderam aprender sobre as propriedades dos materiais e desenvolver a criatividade para decorar o brinquedo com tintas e cores de sua preferência, transformando embalagens de garrafas pet em algo útil e divertido. Dessa forma, mostrou-se que a felicidade não é algo embutido na compra de brinquedos de luxo ou objetos da moda, que é possível usar a imaginação para brincar e se divertir. Ao contrário do que fazem muitos adultos, não é preciso utilizar o ato da compra como um caminho para a felicidade. Devemos sempre pensar no consumo consciente.

\subsection{Depoimento dos pais e diretores das escolas}

Os monitores receberam dos pais das crianças e dos diretores das escolas depoimentos que demonstraram o sucesso do projeto e o quanto este influenciou as pessoas que participam do cotidiano dos alunos. Segundo Elisângela das Graças Guimarães, mãe do aluno Daniel, o filho aprendeu muito sobre reciclagem e passou a ter um novo olhar para o lixo. Ela fez voto para que o projeto continuasse por muitos anos.

Na avaliação de Cíntia Aparecida da Silva Rodrigues, mãe do aluno João Henrique, terceiro colocado na gincana, o filho mudou muito a forma de tratar o lixo ao participar do projeto. Ela registrou que ele passou a pegar todo o lixo reciclável que via, separar e colocar no quarto dele para levar para a Cantaria. Além disso, afirma que foi bom porque ela aprendeu com o filho a separar o lixo.

No entendimento de Cleide Cristina Guimarães Nonato, mãe do primeiro colocado Luiz Carlos, o filho desenvolveu a aprendizagem desde que entrou no projeto Cantaria, principalmente porque o projeto trouxe a oportunidade de sair um pouco da televisão e do computador e ocupar as tardes nas aulas. Sobre a reciclagem, ela diz que aprendeu com ele e o ajudou na coleta do lixo reciclável, recolhendo na casa de sua mãe e de seu irmão para levar para a Cantaria. Segundo ela, o filho passa em frente a uma lixeira e tem outra visão sobre o lixo gerado pelas pessoas e pretende continuar separando o lixo e levando nos pontos decoleta de Ouro Preto.

Registra-se, ainda, a avaliação de Maurílio A. Carmo, pai de Maria Clara, segunda colocada na gincana. Para dele, além de olhar sempre o que estavam jogando no lixo em casa para levar para a Cantaria, sua filha também separou livros e outras coisas que não usava com o intuito de reciclar. Relata, ainda, que ela ficou mais independente e autoconfiante, sabendo que estava fazendo o certo.

$\mathrm{Na}$ opinião de José César de Sousa, diretor da Escola Municipal Izaura Mendes, é importante que o projeto como um todo continue com a mesma seriedade e compromisso com a sociedade. Segundo ele, os professores que tiveram o privilégio de vivenciar esse projeto 
avaliam positivamente o envolvimento e o progresso de cada aluno na escola, no dia a dia e nas ações mais simples, como o cuidado com o próprio lixo.

\subsection{Investimentos futuros}

Com o sucesso da gincana de reciclagem desenvolvida pelo projeto, decidiu-se comprar uma caçamba para melhorar a infraestrutura do espaço, possibilitando o armazenamento do lixo doméstico reciclável que será trazido pelas crianças nos semestres seguintes. Ademais, a caçamba viabiliza a gincana e, consequentemente, a continuação da premiação das crianças como forma de incentivo para um aprendizado efetivo, além de contribuir para uma sociedade consciente de seu papel de ensinar as novas gerações a cuidar do lixo gerado.

É importante reforçar que o lixo armazenado na caçamba será coletado pela Associação assim que a mesma atingir o limite. Mas, durante o período que permanecer no projeto, o material recolhido estará armazenado corretamente, evitando-se atrair animais peçonhentos devido à presença de sujeira e restos de matéria orgânica provenientes do lixo.

\section{CONSIDERAÇÕES FINAIS}

Houve mudanças comportamentais no cotidiano das crianças, como observado pelos pais e diretores das escolas, e tais mudanças superaram as expectativas iniciais da equipe que elaborou e pensou nessa nova vertente do projeto. Pode-se afirmar que muitas crianças aderiram e levaram para suas casas os conhecimentos adquiridos na Cantaria, conscientizando também seus familiares, vizinhos e amigos.

Vale ressaltar a importância de os alunos adquirirem hábitos de reciclagem enquanto crianças. Isso implica na implementação da cultura da reciclagem, ou seja, para que uma atividade seja praticada ao longo de toda uma vida, é preciso criar um hábito. Além disso, a cultura da reciclagem influencia as pessoas do convívio dessas crianças, como pais, irmãos, amigos e demais familiares, a praticarem a separação e a reciclagem do lixo. Portanto, as crianças são as principais disseminadoras dessa cultura de preservação ambiental.

Finalizou-se o projeto no segundo semestre de 2019 com o total de 202,18 kg de lixo reciclável. Esse resultado demonstra o engajamento significativo e a dedicação dos alunos das escolas públicas municipais de Ouro Preto. Além disso, os depoimentos colhidos de pais, diretores e coordenadores pedagógicos das escolas apresentam o amplo alcance que essa nova vertente de Reutilização, Separação e Reciclagem do Lixo obteve, incentivando, assim, a continuação nos próximos semestres com o aperfeiçoamento da infraestrutura do local na Universidade para o recebimento do lixo trazido pelas crianças. Dessa forma, o projeto continuará a beneficiar toda a comunidade da cidade de Ouro Preto e, principalmente, o meio ambiente.

\section{REFERÊNCIAS}

ASSESSORIA DE COMUNICAÇÃO - PREFEITURA DE OURO PRETO. Projeto reciclar pelo Brasil contempla Associação de Catadores de Material Reciclável do Padre Faria, Ouro Preto - MG. Jornal Voz Ativa. Disponível em: <http://www.jornalvozativa.com>. Acesso em: 05 maio 2020.

COELHO, M. Produção de lixo no Brasil cresce mais que capacidade para lidar com resíduos. Estadão. Disponível em: <http://www.estadao.com.br>. Acesso em: 15 maio 2020. 
LOPES, A. A importância da reciclagem para evitar problemas ambientais causados pelo lixo doméstico. Canoas, 2007.

MARODIN, V. S, MORAIS, G. A. Educação Ambiental com os temas geradores lixo e água e a confecção de papel reciclável artesanal. Anais do $2^{\circ}$ Congresso Brasileiro de Extensão Universitária. Belo Horizonte. UEMS. Disponível em: <http://www.ufmg.br/congrext/educa/>. Acesso em: 05 maio 2020.

MEDEIROS, A; et al. A importância da educação ambiental na escola nas séries iniciais. Revista Faculdade Montes Belos, v.4, n.1, set. 2011.

MUCELIN, C.; BELLINI, M. Lixo e impactos ambientais perceptíveis no ecossistema urbano. Sociedade \& Natureza, Uberlândia, 20 (1): 111-124, jun. 2008

RODRIGUES, F. L, CAVINATTO, V. M. Lixo. De onde vem? Para onde vai? São Paulo: Editora Moderna. 1997.

VALLE, H.; NOBRE, L. Reciclar é vida: Educando para transformar. Revista Comunicação e Educação Ambiental, Volume 2, n. 1. Rio Grande, RS. 2012

\title{
CANTARIA PROJECT - EDUCATION AND ART FOR CHILDREN: REUSE, SEPARATION AND RECYCLING OF GARBAGE
}

\begin{abstract}
The "Education and Art for Children" extension project, which in 2020 celebrates its 20th anniversary, is developed in the Department of Mining Engineering at UFOP and encompasses the Ouro Preto community, graduates from different courses and children aged 11 years from schools. public schools in Ouro Preto. Working, over the years with heritage education, citizenship and ethics, the project recently decided to expand its scope for waste with a focus on the reuse, separation and recycling of household waste, creating in children awareness of the importance of each one taking care of their own garbage and the need for conscious consumption. To this end, a gymkhana was set up in which the children were instructed to separate the recyclable waste generated at home and take it to the project's facilities throughout the semester. The monitors were responsible for receiving, accounting, and correct separation of these materials that would be destined for garbage. In order to work on the concept of reuse, toys were created with part of the collected material, thus allowing children to develop their imagination and creativity. Students who brought the largest amount of recyclable waste were awarded first, second and third. At the end of the project, $202 \mathrm{~kg}$ of recycled material were counted and donated to the association of garbage collectors called "Ouro Preto Recicla". Finally, it highlights the importance of creating citizen practices, which, like this project, contribute to the formation of conscious, critical and committed children with the future of the planet.
\end{abstract}

Keywords: Children. Reuse. Separation. Recycling. Trash. 